\title{
Correction to: Opportunities for reproductive tourism: cost and quality advantages of Turkey in the provision of in-vitro Fertilization (IVF) services
}

\author{
M. S. Yildiz and M. Mahmud Khan ${ }^{2,3^{*}}$
}

\section{Correction}

After the publication of this article [1] we were made aware that the affiliation for the first author was shown incorrectly as "Ministry of Health, Ankara, Turkey". The correct affiliation is "Internal Audit Department, Turkey Ministry of Health, Ankara, Turkey" and has been included in this correction.

\footnotetext{
Author details

'Internal Audit Department, Turkey Ministry of Health, Ankara, Turkey.

${ }^{2}$ Department of Health Services Policy and Management, University of South Carolina, 915 Greene Street, \#357, Columbia, SC 29208, USA. ${ }^{3}$ Department of Health Services Administration, China Medical University, Taichung City,

Taiwan.
}

Published online: 06 November 2017

\section{Reference}

1. Yildiz MS, Khan MM. Opportunities for reproductive tourism: cost and quality advantages of Turkey in the provision of in-vitro Fertilization (IVF) services. BMC Health Serv Res. 2016;16:378. https://doi.org/10.1186/s12913-016-1628-7.

\footnotetext{
*Correspondence: mkhan@mailbox.sc.edu

${ }^{2}$ Department of Health Services Policy and Management, University of South Carolina, 915 Greene Street, \#357, Columbia, SC 29208, USA

${ }^{3}$ Department of Health Services Administration, China Medical University,

Taichung City, Taiwan
} 